\title{
Evaluation of Antibacterial Activity and Phytochemical Constituents of Leaf Extract of Lippia adoensis
}

\author{
Yared Wasihun ${ }^{1}$, Tesfalem Adraro ${ }^{2}$, Solomon $\mathrm{Ali}^{3}$
}

${ }^{1}$ Department of Biomedical Sciences, College of Public Health and Medical Sciences, Jimma University, ETHIOPIA

${ }^{2}$ Department of Pharmacy, College of Public Health and Medical Sciences, Jimma University, ETHIOPIA

${ }^{3}$ Department of Medical Laboratory and Pathology, College of Public Health and Medical Sciences, Jimma University, ETHIOPIA

\begin{abstract}
There are quite large numbers of traditionally used medicinal plants that are used to treat skin disorder in the ethno medical system of Ethiopia. Medicinal plants namely L. adoensis, was screened for antibacterial activity against different strains of bacteria which are known to cause various types of skin infections and food poisoning

Anti bacterial effect of the plant species was evaluated against different bacterial strains. The leaves of plant species were extracted by maceration and soxhelt extraction technique for preparation of crude and fractional extract respectively. And anti bacterial screening of different concentration of both crude and fractional extract of the plant species were determined using agar well diffusion method. The test organisms were one gram positive (S.aures) and three gram negative (Salmonella typhi, E.coli and P.aeruginosa) standard organisms.

The results of the initial antibacterial screening test indicated the potential of these herbal drugs in treating bacterial infections of the skin and food poisoning. Among the different fractions (petroleum ether, chloroform, acetone and methanol) tested for antibacterial activity, the non-polar fractions were found to be more active than the polar fractions. The Phytochemical screening tests carried out on L. adoensis indicated the presence of tannins, flavonoids and saponins.

Different extracts L.adoensis were showed significant antibacterial activity against the S.aueres, P.aeroginosa, E.coli and S.typhi. Hence further study is recommended to identify the specific active ingredient and potential formulation of effective antibiotic.
\end{abstract}

Key Words: Antibacterial activity, Phytochemical screening, plant species Lippia adoensis

\section{INTRODUCTION}

Even if there is progress of prevention and treatment of infectious disease, it is responsible for worsening the living condition of many million people around the world. Infectious disease is 
the world's biggest killer of children and young adults. According to WHO report every year approximately 13 million people die of infectious diseases. Half of these deaths are from developing countries. Every hour around 1500 people die due to infectious diseases, majority of them are children. More over infectious disease is severe in countries which have unsanitary living conditions and malnutrition problem like Ethiopia.

Infectious/Communicable disease is caused by microorganism like bacteria, virus, fungus, parasite and other microbes. Bacterial infectious disease is most commonly caused by gram positive and gram negative bacteria. From gram positive bacteria S.aureus is known to cause different diseases like food poisoning, skin infection, wound infection and respiratory tract infection. Gram negative bacteria like E.coli, Salmonella and Shigella are commonly known to cause Gastro intestinal tract infection.

Previously with the advent of antimicrobials some Medical professional believed that the problem of infectious disease is over, but latter they understand microbes also arise with new survival strategies. Newly discovered and emerging infectious agents start to appear. Antimicrobial resistance is a worldwide problem. However the situation in developing countries is especially serious due to scarcity of modern medicine, poor primary health care and poverty (Inanir etal, 2002).

Infectious disease can be cured and controlled but appropriate drugs are critically important. In order to formulate potent anti-microbial drugs, plants used by herbalists are one of the possible options. It is believed that the increased use of plant medicine by different people of the world has potential for finding new and effective noble drugs.

According to literatures Many medicinal plants of Africa have been investigated for their chemical components. Accordingly some of the isolated compounds have been shown to possess interesting biological activities. for instance Garicinia cola, Aframomum melegueta, Xylopia aethiopica, Cryptolepis sanguinolent and Chasmanthera dependens were found to possess different groups of compounds with wide ranging anti-inflammatory and antimicrobial activities (Taylor, 2000).

On the other hand Ethiopia is well known for its significant geographical diversity, which favored formation of different Habitat and vegetation zones. It is estimated that Ethiopia has a plant flora of about 700 specious. Moreover, about $12 \%$ of these plants are endogenous. The country Has high diversity of traditional knowledge and practice of the people (Evans, 2000). Even if traditional medicine has become an integral part of the cultures due to its long history, it experienced very little attention in modern research and development. For instance "Zingibil,Teji sar,Tenadam and Lippia adonensis were commonly used by different traditional medical practitioners (Evans, 2000).

Lippia adoensis is included under Verbenaceae that is a large family with about 70 to 80 genera and over 3,000 species; distributed throughout the world mainly in the tropics and temperate regions. In Ethiopia, the family is represented by 9 genera and 30 species. Lippia is a genus with 200species in tropical Africa and America. Five species have been described in the country. L.adoensis (locally known as "Kesse") is a shrub having a height of 1 to 3 meters. Two varieties are recognized in Ethiopia, the wild variety (var. adoensis) and the cultivated variety (var.koseret) (Toshihiro etal, 1992).

In Ethiopia, Lippia adoensis extracts were used medicinally by a variety of indigenous people for treatment of skin infection. However little is known about the chemical constituents present in the plant. Information on the biological activities of this plant including its anti microbial property are sketchy. The essential oil has been investigated but only a small fraction were identified .Chemical characterization of the oils imperative to determine the commercial value 
and potential application .A rapid, simple method through a chemical marker, which can be used to evaluate the anti microbial activity and Phytochemical screening of Lippia adoensis is important. Hence this study was done to assess the anti bacterial activity and phytochemical constituents of leaf extract of Lippia adoensis.

\section{Methodology}

Descriptive study design was conducted in laboratories of department of chemistry, biochemistry and Medical microbiology at Jimma University. The leaves of Lippia adoensis were collected, characterized in Jimma university herbarium and deposited there. All parts of the plant materials were dried in an open air protected from direct exposure to sunlight. The dried plant materials were separately powdered to suitable size and made ready for extraction.

\section{Preparation of the Fractional Extracts}

Fifty gm of leaf powder was extracted with $80 \%$ methanol by maceration. This was continued for 48 hours with frequent agitation and the resulting liquid was filtered by using filter paper. Extraction was repeated five times and the filtrates of all portions were combined in one vessel. The organic solvent was removed by evaporation using rota vapor at not more than $40^{\circ} \mathrm{C}$. The aqueous residue was then placed in an oven at $40^{\circ} \mathrm{C}$ for about 48 hours to remove the water. The resulting dried mass was converted to powder then, packed into a glass vial and stored in desiccators over silica gel until use. Likewise hundred gm of L. adoensis was extracted with petroleum ether, chloroform, acetone and methanol by the use of soxhelt extraction technique. Polarity gradient extraction (PGE) was operated by injecting four solvents into parts of extraction column .Each solvent was removed by evaporation using a rota vapour and the fractions were then placed in an oven at not more than $40^{\circ} \mathrm{C}$ for about 24 hours to remove any residual solvent. The resulting semisolid mass of each fractional extracts was stored in desiccators until use in the same way as the crude extract.

\section{Antibacterial Screening of the Crude Extracts and Fractions}

The antibacterial activities of the hydro-alcoholic extracts of the plant species was determined using agar well diffusion method. Eighty percent Methanol, methanol and chloroform were used as negative controls during the whole test on bacteria.

Standard bacteria strains of human pathogens were used for screening of anti microbial activity. These are one gram positive (s.aures (ATCC25925)) and three gram negative [E.coli (ATCC25922), salmonellatyphi (ATCC83859) and P.aeruginosa (ATCC27853)].All slandered organisms were first grow on $5 \%$ sheep red blood agar plates. Few colonies (4 to 5 ) of similar morphology of the respective bacteria were transferred with a sterile inoculating loop to a liquid medium (peptone water) and incubated until adequate growth of turbidity equivalent to McFarland 0.5 turbidity standard was obtained. The inoculums of the respective bacteria were streaked on to the Mueller Hinton agar plates using a sterile swab in such a way as to ensure thorough coverage of the plates and a uniform thick lawn of growth following incubation. Wells of $10 \mathrm{~mm}$ in diameter were formed on to Mueller Hinton plates using a sterile cork borer. The wells were filled with the test agents $(100 \mu \mathrm{l})$ each and the plates were allowed to stay for 1 to 2 hours at room temperature. Finally, the plates were then incubated at $37^{\circ} \mathrm{C}$ for 18 to 24 hours. The resulting diameters of zones of inhibition were measured and recorded in $\mathrm{mm}$. Gentamycin was used as a positive control at a concentration of $0.1 \mathrm{mg} / \mathrm{ml}$. Moreover tube dilution method was performed to determine the minimum inhibitory concentration of the crude extracts. 


\section{Phytochemical Screening}

Extracts of the plant species namely L. adoensis, was subjected to Phytochemical screening using standard screening procedures. For alkaloids; $0.5 \mathrm{~g}$ crude extract was stirred with $5 \mathrm{ml}$ of $1 \% \mathrm{HCl}$ on a steam bath. $1 \mathrm{ml}$ of the filtrate was treated with a few drops of Mayer's reagent and another $\mathrm{ml}$ was similarly treated with Dragendorff's reagent. Turbidity or precipitation with both reagents was taken as preliminary evidence for the presence of alkaloids. For saponins; $0.5 \mathrm{~g}$ of crude plant extract was shaken with water in a test tube. Frothing which persists on warming was taken as preliminary evidence for the presence of saponins. by using Chloroform - glacial acetic acid - methanol - water (64:32:12:8) as a mobile phase and vanillin-sulphuric acid as a spraying reagent for detection. Formation of a blue, blue violet, red or yellow brown zone is considered as positive test for saponins [18-20]. For tannins; $0.5 \mathrm{~g}$ crude extract was stirred with $10 \mathrm{ml}$ of distilled water and filter. The addition of $\mathrm{FeCl} 3$ reagent to the filtrate resulting in blue, blue-black, green or blue-green coloration or precipitation was taken as evidence for the presence of tannins. For anthraquinones; A sample $(5 \mathrm{~g})$ of L.adoensis extract was shaken with $10 \mathrm{ml}$ of benzene and filter. A $10 \%$ ammonium hydroxide solution $(5 \mathrm{ml})$ was added to the filtrate and the mixture was shaken. The presences of a pink, red or violet color in the ammoniacal phase was taken as an indication of the presence of Anthraquinones. For poly phenols; for $2 \mathrm{ml}$ of the aqueous solution of the crude extract, 3 drops of a mixture of $1 \mathrm{ml} \mathrm{1 \%} \mathrm{FeCl3} \mathrm{and} 1 \mathrm{ml} 1 \%$ $\mathrm{K} 3 \mathrm{Fe}(\mathrm{CN}) 6$ were added. Formation of green blue color was taken as an indication of the presence of Polyphenols. For flavonoids, for $2 \mathrm{ml}$ of the alcoholic solution of the crude extract 4 drops of $2 \%$ lead acetate solution were added. The development of yellow or orange color was taken as an indication of the presence of flavonoids.

\section{RESULTS}

The study showed that on the antibacterial activities of the leaf extract of L. adoensis and its phytochemical constituents. The fresh leaves of this plant have very high water content and shrink extremely to a light weight dried mass with a partial loss of its green color. In general, the yields obtained from the plant are quite adequate. The largest yield was recovered from methanol fractional extract. The solvents used for extraction and reconstitution of the extracts were water, ethanol petroleum, acetone and ether. None of this chemical showed significant activity against tested bacteria. The results of the antimicrobial screening assay of the crude extracts of L.adoensis on the selected bacterial strains indicated that all the extracts of L. adoensis shows significant activity against tested bacteria with varying zone of inhibition (Table 2). The petroleum ether extract was the most active of the four extracts. It showed activity against all the organisms tested. The results illustrated that the non-polar fractions (i.e. petroleum ether and chloroform) were stronger in their activity compared to the relatively polar fractions (Table 2). The MIC values indicated that $2.5 \mathrm{mg} / \mathrm{ml}$ extracts of L.adoensis inhibited the growth of Pseudomonas aeroginosa, Salmonella and Staphylococcus aureus (Table 3). The leaves of L. adoensis were screened for the presence of different Phytochemical compounds of therapeutic interest using chemical (Table 4). 
Asia Pacific Journal of Energy and Environment, Volume 1, No 1 (2014)

Table 1. Percentage Yields of Different Fractions of L. adoensis leaf extract. Jimma zone Oromia region June 2010

\begin{tabular}{llll}
\hline S.N. & Extraction technique & Wt.in gram & $\%$ of yield w/w \\
1 & Methanol fractional extract & 0.124 & 12.4 \\
2 & Crude extract & 5.02 & 10.02 \\
3 & Petroleum ether fractional extract & 0.0221 & 2.21 \\
4 & Chloroform fractional extract & 0.0150 & 1.50 \\
5 & Acetone fractional extract & 0.0690 & 6.90 \\
\hline
\end{tabular}

Table 2. Antibacterial Activities of Different Fractions of L. adoensis against Selected Strains of Bacteria Jimma zone Oromia region June 2010

\begin{tabular}{|c|c|c|c|c|c|}
\hline \multirow[t]{2}{*}{ Fraction of extract } & \multirow{2}{*}{$\begin{array}{l}\text { Concen } \\
\text { tration } \\
\mathrm{mg} / \mathrm{ml}\end{array}$} & \multicolumn{4}{|c|}{ Bacterial strain Zone of inhibition ( $\mathrm{mm}$ ) } \\
\hline & & $\begin{array}{l}\text { SA } \\
\text { (ATCC } \\
25925 \text { ) }\end{array}$ & $\begin{array}{l}\text { EC } \\
\text { (ATCC } \\
\text { 25922) }\end{array}$ & $\begin{array}{l}\text { PA } \\
\text { (ATCC } \\
27853 \text { ) }\end{array}$ & $\begin{array}{l}\text { Sal } \\
\text { (ATCC } \\
83859 \text { ) }\end{array}$ \\
\hline \multirow[t]{3}{*}{ Petroleum ether } & 75 & 37 & 24 & 18 & 20 \\
\hline & 50 & 33 & 22 & 18 & 18 \\
\hline & 25 & 29 & 18 & 17 & 16 \\
\hline \multirow[t]{3}{*}{ Chloroform } & 75 & 33 & 19 & 20 & 23 \\
\hline & 50 & 27 & 18 & 19 & 20 \\
\hline & 25 & 34 & 16 & 17 & 19 \\
\hline \multirow[t]{3}{*}{ Acetone } & 75 & 31 & 19 & 21 & 20 \\
\hline & 50 & 29 & 16 & 19 & 19 \\
\hline & 25 & 24 & 14 & 16 & 15 \\
\hline \multirow[t]{3}{*}{ Methanol } & 75 & 30 & 20 & 21 & 21 \\
\hline & 50 & 26 & 19 & 17 & 19 \\
\hline & 25 & 22 & 16 & 15 & 18 \\
\hline \multirow[t]{3}{*}{ crude } & 75 & 32 & 19 & 23 & 24 \\
\hline & 50 & 25 & 18 & 21 & 20 \\
\hline & 25 & 21 & 16 & 19 & 17 \\
\hline Gentamycine & 0.1 & 29 & 22 & 21 & 22 \\
\hline
\end{tabular}

$\mathrm{Sa}=$ S. aureus, $\mathrm{Ec}=$ E. coli, $\mathrm{Pa}=$ P. aeruginosa, sal =salmonela thyphi

Table 3. Minimum Inhibitory Concentration (MIC) Values of the crude (80\% Methanol) Extracts of L.adoensis on the Tested Strains Jimma zone Oromia region June 2010.

\begin{tabular}{llllll}
\hline Plant species & $\begin{array}{l}\text { Concen } \\
\text { tration }\end{array}$ & \multicolumn{2}{l}{ Bacterial strain } & & \\
& $\mathrm{Sa}$ & Ec & Pa & Sal \\
& $\mathrm{mg} / \mathrm{ml}$ & (ATCC & (ATCC & (ATCC & (ATCC \\
Lippia adoensis & & $25925)$ & $25922)$ & $27853)$ & $83859)$ \\
& 20 & - & - & - & - \\
& 10 & - & - & - & - \\
& 5 & - & + & - & - \\
& 2.5 & - & + & - & - \\
& 1.25 & + & + & + & + \\
& 0.625 & + & + & + & + \\
\hline
\end{tabular}

$(+)=$ presence of growth, $(-)=$ absence of growth, $\mathrm{Sa}=S$. aureus, $\mathrm{Ec}=E$. coli, $\mathrm{Pa}=$ P.aeruginosa, Sal=salmonella 
Table 4. Phytochemical screening of crude ( $80 \%$ methanol) extract of the Leaves of $L$. adoensis using chemical test methods Jimma zone Oromia region June 2010.

\begin{tabular}{ll}
\hline Metabolites tested for & crude $(80 \%$ methanol $)$ extract of L. adoensis \\
Alkaloids & + \\
Saponins & + \\
Tannins & ++ \\
Anthraquinones & - \\
Polyphenols & + \\
flavonoids & + \\
\hline
\end{tabular}

- = negative,$++=$ strongly positive,$+=$ positive

\section{Discussion}

In our study it was observed that the percentage yields obtained from successive extraction of these plants indicated that increasing polarity of the extracting solvent increases the yield except chloroform which afforded quite low yield compared to petroleum ether. As a result, methanol, which is the most polar of all solvents used for fractionation, afforded the maximum yield .These fractions were then tested against the selected bacterial strains on which the crude extract showed activity.

The extracts of the Lippia adoensis species were screened for biological activity against different strains of bacteria. The antibacterial activity-screening tests were carried out on organisms that are known to be among the most common causative agents of both primary and secondary infectious skin disorders. L. adoensis was also found to be active on at least one of the selected bacterial strains. When the antibacterial activities of this herbal drug were compared to that of the positive controls, many of them (L. adoensis at a concentration of $75 \mathrm{mg} / \mathrm{ml}$ ) were found to have almost comparable activity to the standard gentamycin against bacteria. L. adoensis at a concentration of $100 \mathrm{mg} / \mathrm{ml}$ was found to have greater activity against bacteria as compared with standard gentamycin. In some cases, antibacterial activities observed were even greater than the positive controls activities for example, $L$. adoensis against $S$. aureus. In comparison with similar study done in Addis Ababa University, Ethiopia, The finding of this study is consistent, the antibacterial activity of the tested palnt showed that the zone of inhibitions increased with an increase in concentration. (Tadeg etal, 2004).

In our study the antibacterial activity profile of the plant species against the tested strains indicated that $S$. aureus was the most susceptible bacterium of all the bacterial test strains. On the other hand, E. coli was found to be the most insensitive strain of all bacteria. In fact, gram-negative bacteria are frequently reported to have developed multi drug resistance to many of the antibiotics currently available in the market of which E. coli is the most prominent. Therefore, it is not surprising to learn that E. coli is the least responding bacterial strain to the tested plant extracts (Salman etal, 2008).

The antibacterial activity was more pronounced on the gram-positive bacteria ( $S$. aureus) than the gram-negative bacteria (E. coli, salmonella typhi and P. aeruginosa). The reason for the difference in sensitivity between gram-positive and gram-negative bacteria might be ascribed to the differences in morphological constitutions between these microorganisms, gram-negative bacteria having an outer lipopolysacharide membrane. This makes the cell wall impermeable to antibacterial chemical substances. The gram-positive bacteria on the other hand are more susceptible having only an outer peptidoglycan layer which is not an effective permeability barrier. Therefore, the cell walls of gram negative organisms are more 
complex in lay out than the gram positive ones acting as a diffusion barrier and making them less susceptible to the antibacterial agents than are gram positive bacteria (Alonso etal, 2000).

In spite of this permeability differences, however, some of the extracts have still exerted some degree of inhibition against gram-negative organisms as well. Several reports have indicated that infectious skin disorders are very common in Ethiopia. Among the pathogens most commonly known to cause infectious disorders of the skin is S. aureus (Hodges, 2002). Thus, Lippia adoensis showed activity against $S$. aureus might justify the extensive use of these agents for the treatment of skin disorders. In all species of plants tested for antibacterial activity, the zone of inhibitions increased with an increase in concentration i.e. stronger activity was observed at $100 \mathrm{mg} / \mathrm{ml}$ than lower concentrations. This study illustrated that the non-polar fractions (i.e. petroleum ether and chloroform) were stronger in their activity compared to the relatively polar fractions (i.e. acetone and methanol). Antibacterial activities were found to decrease with increasing polarity indicating that the active compounds responsible for antibacterial activities of the extract reside in the non-polar fractions in relatively higher concentrations. The MIC values indicated that extracts of L. adoensis were more potent against bacteria. $P$. aeruginosa was more sensitive to the antibacterial agents from among gram-negative bacteria being inhibited at $2.5 \mathrm{mg} / \mathrm{ml}$ by L. adoensis crude extracts. The MIC values of the extracts on S. aureus was found to be $2.5 \mathrm{mg} / \mathrm{ml}$ (L. adoensis) .The overall antibacterial activity screening results is still indicative of the potential of these herbal drugs as effective medicaments in the treatment of infectious skin disorders.

The leaves of $L$. adoensis were screened for the presence of different Phytochemical compounds of therapeutic interest. L.adoensis showed positive test for the presence of alkaloids, saponins, polyphenols, flavonoids and tannins. Numerous studies conducted on the antimicrobial activities of the class of compound listed above reported the potential of each class of compound in inhibiting the growth of wide ranges of microorganisms. Phenolics and polyphenols are compounds having such potential. Reaction with sulfahydryl groups or more non-specific reactions with proteins is thought to be the possible mechanism for phenolic toxicity to microorganisms (Scalbert, 1991). Flavonoids and flavonoid-derived plant natural products have long been known to function as antimicrobial defense compounds (Kazmi etal, 1994). Different in vitro studies have shown that they are effective antimicrobial substances against a wide spectrum of microorganisms.

\section{Conclusions AND ReCOMmendation}

Antibacterial activity profile of L. adoensis against the tested strains indicated that $S$. aureus was the most susceptible and E. coli was found to be the most insensitive strain of all bacteria. Lippia adoensis showed activity against $S$. aureus might justify the extensive use of these agents for the treatment of skin disorder. Phytochemical screening study on L. adoensis showed positive test for the presence of alkaloids, saponins, Polyphenols, flavonoids and tannins. The result from this study has shown that indicating their potential in treating infectious diseases of the skin. The possible synergistic effect between different combinations of these extracts must be taken into account. This speculation needs further study.

\section{REFERENCES}

Abate, G., (1989), Etse Debdabe, Ethiopian Traditional Medicine, Demissew, S. (Editor), Department of Biology, Science Faculty, Addis Ababa University. 
Abegaz, B., Asfaw, N. and Lwande, W. Constituents of Essential Oils from Wild and Cultivated Lippia adoensis, J. Essent. Oil Res.1993;5: 487-491.

Alonso, R., Fernandez-Aranguiz, A., Colom, K., Herreras, A., Cisterna, R. (2000), Profile of Bacterial Isolates and Antimicrobial Susceptibility: Multicenter Study Using a One-day Cut-off, Rev. Esp. Quimioter. 2000; 13(4): 384- 393

Asres, K. and Bucar, F. Lippia adoensis var. adoensis: Studies on the Essential Oil Composition and Antioxidant Activity, Ethiop. Pharm. J.2002; 20:32-38.

Asres, K., Bibbons, W., David, P. and Polo, M. Alkaloids of Ethiopian Calpurniaaurea, subsp. aurea, Phytochemistry, 1986; 25(6): 1443-1447.

Baquar, S. R. The Role of Traditional Medicine in Rural Environment, In: Traditional Medicine in Africa, Issaq, S. (Editor), East Africa Educational Publishers Ltd.,1995;Nairobi, pp. 141-142.

Dixon, R. A., Steel, C. L. Flavonoids and Isoflavonoids - a Gold Mine for Metabolic Engineering, Trends Plant Sci. 1999; 4(10): 394-400.

Evans, W. C. (2000), Trease and Evans Pharmacognosy, 15th Edition, W. B.Sounders, London, pp. 34,488-491.

Farnsworth, N. R. Biological and Phytochemical Screening of Plants, J. Pharm.Sci.1966 ; 55(3): 225-269.

Hailu Tadeg, Endris Mohammed, Kaleab Asres, Tsige Gebre-Mariam. Performance evaluation of topical formulations of the crude extracts of L. adoensis and O. rochetiana. Ethiopian Pharmaceutical Journal, 2004;22: 15-26.

Hiletework, M. Skin Diseases Seen in Kazanchis Health Center, Ethiop. Med. J.1998; 36(4): 245-54.114

Hodges, N. (2002), Pharmaceutical Applications of Microbiological Techniques, In: Pharmaceutics, The Science of Dosage Form Design, 2nd Edition, Aulton, M. E. (Editor), Harcourt Publishers Limited, London, p. 606.

Inanir, I., Sahin, M., Gunduz, K., Turel, A. and Ozturkan, S. Prevalence of Skin Conditions in Primary School Children in Turkey: Difference Based on Socio economic Factors, Pediatr. Dermatol.2002; 19(4): 307-311.

Kazmi, M., Malik, A., Hameed, S., Akhtar, N. and Noor Ali, S. An Anthraquinone Derivative from Cassia italica, Phytochemistry, 1994;36: 761-763.

Mason, T. L. and Wasserman, B. P. Inactivation of Red Beet Beta- glucan Synthase by Native and Oxidized Phenolic Compounds, Phytochemistry, 1987;26: 2197-2202.

Meng, J. C., Zhu, Q. X., and Tan, R. X. New Antimicrobial Mono and Sesquiterpenes from Soroseris hookeriana Subsp. erysimoides, Plant Med. 2000; 66(6): 541-4.

Meyer, J. Afolayan, A. , Taylor, M. and Erasmus, D. Antiviral Activity of Galangin From the Aerial Parts of Helichrysum aureo-nitens, J. Ethnopharmacol.1997; 56: 165-169.

Nakahara, K., Kawabata, S., Ono, H., Ogura, K., Tanaka, T., Ooshima, T. and Hamada, S. Inhibitory Effect of Oolong Tea Polyphenols on Glu-cosyltransferases of Mutans streptococci, Appl. Environ. Microbiol.1993;59: 968-973.193.

Odebiyi, O. O. and Sofowora, E. A. (1978), Phytochemical Screening of Nigerian Medicinal Plants II, J. Nat. Prod.1987; 41(3): 234-246.

Rauha, J., Remes, S., Heinonen, M., Hopia, A., Kahkonen, M., Kujala, T.,Pihlaja, K.,Vourela, H. and Vourela, P. Antimicrobial Effects of Finnish Plant ExtractsContaining Flavonoids and Other Phenolic Compounds, Int. J. Food Microbiol. 2000; 56(1): 3-12.

Rosa, G. M., Pacilio, M., Carlo, G. D., Esposito, E., Pinto, L. and Meli, R. In Vivo and In Vitro Antiinflammatory Effect of Echinacea purpurea and Hypericum perforatum,2002; 54: 1379-1383.

Salman, M.T., R.A. Khan and I. Shukla. Antimicrobial activity of Nigella sativa Linn. Seed oil against multidrug resistant bacteria from clinical isolates. Natural Product Radiance, 2008; 7(1): 10-14.

Satima, F. T., Mc Birde, S. R. and Leppard, B. Prevalence of Skin Disease in Rural Tanzania and Factors Influencing the Choice of Health Care Modern or Traditional, Archives of Dermatology, 1999;134(11): 1050-1055.

Satish, S. Antibacterial effects of herbal extracts. World Journal of Agricultural Sciences, 2008; 4 (S): 839843.

Scalbert, A. Antimicrobial Properties of Tannins, Phytochemistry, 1991;30: 3875-3883

Serafini, M., Ghiselli, A. and Ferro-Luzzi, A. Red Wine, Tea and Antioxidants, Lancet, 1994; 344: 626. 
Asia Pacific Journal of Energy and Environment, Volume 1, No 1 (2014)

Sertie, J. A., Basile, A. C., Panizza, S., Matida, A. K. and Zelnik, R. J. Pharmacological Assay of Cordia Verbenaceae, Part I: Anti-inflammatory Activity of the Crude Extract of the Leaves, Planta medica, 1988; 54(1): 7-10.

Shakkoury, W. and Abu-Wndi, E. Prevalence of Skin Disorders Among Male Schoolchildren in Aman, Jordan, Archives of Dermatology, 1999;5(5): 955-959.

Sofowora, A. (1982), Medicinal Plants and Traditional Medicine in Africa, John Wiley and Sons Ltd., New York, pp. 142-146.

Taylor, L. (2000), Plant Based Drugs and Medicine, Raintee Nutrition Inc., pp.1-5.

Toshihiro, A., Gebreyesus, T., Hiroshi, H. and Toshitake, T. Co- occurrence of C- 24 Epimeric 24ethylsterols Possessing and Lacking a 25 bond in Kalanchoe petitiana, Phytochemistry, 1992;31: 163-166.

Tyler, V. E., Brady, L. E., and Robbers, J. E. (1976), Pharmacognosy, $7^{\text {TH }}$ Edition, Lea and Febiger, Philadelphia, pp. 1-3.

Vickers, A., and Zollman, C. ABC of Contemporary Medicine, Herbal Medicine, BMJ, 1999;319(16): 1050-1053.

WHO Traditional Medicine Strategy 2002-2005, World Health Organization, Geneva, 2002, pp. 2-5.

Williams, H. New Treatments for Atopic Dermatitis, BMJ, 2002;324:1534-1535.

\section{Why Open Access???}

"In the traditional publishing model, readers have limited access to scientific papers; authors do not have copyright for their own papers, and cannot post their papers on their own websites, which presents a significant barrier to the sharing of knowledge, as well as being unfair to authors. Open access can overcome the drawbacks of the traditional publishing model and help scholars build on the findings of their colleagues without restriction" 